\title{
A 2,2' - DIPIRIDIL CETOXIMA, COMO REAGENTE PARA DETERMINAÇÃO ESPECTROFOTOMETRICA DO COBALTO.
}

\author{
Antonio Octavio Jacintho
}

\begin{abstract}
A presente nota relata alguns aspectos dos estudos preliminares sobre a aplicação da $2,2^{\prime}$ - dipiridil cetoxima como reagente para a determinação colorimétrica do cobalto.

Nesta oportunidade, procurou-se principalmente analisar os problemas decorrentes da aplicação da técnica descrita por HOLLAND \& BOZIC (1968), na determinação do cobalto em plantas.
\end{abstract}

\section{INTRODUÇ̃̃O}

Dentre os inúmeros métodos espectrofotométricos que têm sido propostos para a determinação do cobalto, nos mais diversos materiais, CLARK (1958); SANDELL (1959); HAROLD \& SZOBOLOTZKY (1963); CHARLOT (1964); BURKE \& DEARDORFF (1970) e outros, o que utiliza o sal nitro-R como reagente é o mais amplamente empregado, apesar das dificuldades analíticas que o mesmo apresenta.

Dentre os novos reativos que vêm sendo propostos para a determinação colorimétrica do cobalto, a 2,2' - dipiridil cetoxima apresenta características que poderão permitir a obtenção de uma técnica rápida, sensível e precisa para a avaliação de pequenas quantidades do citado elemento.

O emprego da 2,2' - dipiridil cetoxima como reagente para a determinação quantitativa de cobalto, foi proposto por HOLLAND \& BOZIC (1968). O citado reativo, empregado em solução a $1 \%$ em etanol de 80 a $95 \%$, reage instantaneamente com o cobalto formando um quelato amarelo-esverdeado, solúvel em água e que pode ser facilmente extraído em clorofórmio.

O método proposto poderá apresentar sensibilidade superior ao do sal nitroso-R e é pouco sujeito a interferências. Dentro de limites

* Entregue para publicação em 10/7/72

* Professor Assistente Doutor do Depto. de Química da ESALQ. 
relativamente amplos de concentração, o método segue a lei de Beer e o composto colorido, quando extraído em clorofórmio, apresenta um máximo de absorção entre os limites de 370 a 390 milimicrons de comprimento de onda.

\section{MATERIAL E MÉTODOS}

Diversas modificações e variações da técnica proposta por HOLLAND \& BOZIC (1968), para a determinação do cobalto, estão sendo estudadas com a finalidade de se poder aplicá-la em análise de plantas.

Deste modo, procurou-se inicialmente trabalhar com menores quantidades de cobalto, além de se extrair o composto colorido num menor volume de solvennte.

Paralelamente ao estudo detalhado do método que vem sendo desenvolvido, preparou-se uma solução contendo $\mathrm{Fe}^{3+}, \mathrm{Mn}^{2+}, \mathrm{Zn}^{2+}$,

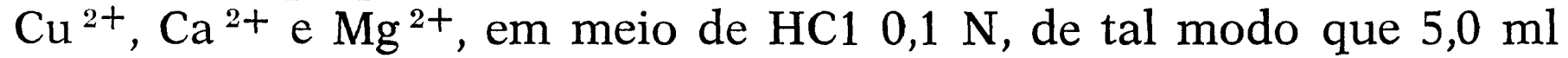
da referida solução corresponderiam a um extrato de planta contendo níveis bem elevados dos principais interferentes do método.

As indicações para resolver os problemas dos interferentes, que HOLLAND \& BOZIC (1968) propuseram, quando efetuaram este estudo isoladamente, não puderam ser empregadas devido ao aparecimento de reações secundárias quando estes interferentes foram estudados conjuntamente.

$\mathrm{O}$ emprego de pirofosfato, para eliminar interferência de $\mathrm{Zn}^{2+}$, $\mathrm{Mn}^{2+}$ e $\mathrm{Fe}^{3+}$ etc., não forneceu resultados satisfatórios.

A interferência do $\mathrm{Cu}^{2+}$ é notória. Tentativas de se solucionar o problema das interferências com fluoretos, trietanolamina, ácido ascórbico, fosfatos e EDTA, foram relativamente infrutíferas.

Porém, pôde ser constatado que a maioria desses problemas poderia ser contornada através do controle do $\mathrm{pH}$.

A reação de formação do quelato de cobalto se processa convenientemente num intervalo de $\mathrm{pH}$ de 7,0 a 8,5 e a sua extração pelo solvente orgânico pode ser realizada numa faixa mais ampla de $\mathrm{pH}$, o que possibilitaria o controle de certos interferentes.

A referida técnica está sendo estudada ao mesmo tempo em que estão sendo testados alguns agentes complexantes. A solução tampão a ser empregada para o controle do $\mathrm{pH}$ ao redor de 7,5, também atua no sentido de reduzir o efeito de alguns íons sobre a determinação do cobalto. 


\section{RESULTADOS OBTIDOS}

A nova técnica forneceu resultados satisfatórios quando aplicada a soluções puras. Quantidades de cobalto, variando de 1 a 10 microgramas, reagem em meio de citrato em $\mathrm{pH}$ ao redor de 7,5 e o composto colorido formado é extraído com $5,0 \mathrm{ml}$ de clorofórmio, fornecendo uma solução linear entre a absorbância e as concentrações de cobalto, conforme pode-se observar através dos dados que seguem:

Relação entre a absorbância e as concentrações de cobalto de soluções padrões. Extração com 5,0 ml de clorofórmio e leituras contra prova em branco a 385 milimicrons de comprimento de onda.

$\begin{array}{cc}\begin{array}{c}\text { Microgramas de cobalto nos } \\ 5,0 \mathrm{ml} \text { do solvente }\end{array} & \text { Absorbância } \\ 0,0 & 0,00 \\ 2,0 & 0,12 \\ 4,0 & 0,24 \\ 6,0 & 0,35 \\ 8,0 & 0,46 \\ 10,0 & 0,58\end{array}$

Em soluções puras, o método apresenta-se bastante preciso.

O estudo dos demais aspectos do método está sendo desenvolvido e novas modificações poderão ser propostas.

Deverá ser recomendada uma técnica para a determinação do cobalto em plantas onde o extrato possa ser preparado a partir de 2,0 ou no máximo 3,0 gramas da amostra.

\section{SUMMARY}

THE 2,2' - DIPYRIDYL KETOXIME, AS REGENT FOR SPECTROPHOTOMETRIC DETERMINATION OF COBALT.

In this short communication the author relates some preliminary studies about the application of 2,2' - dipyridy ketoxime, as reagent for a spectrophotometric determination of cobalt.

Problems that appear in the application of the HOLLAND \& BOZOC (1968) technics for plant analysis, were discussed. 


\section{LITERATURA CITADA}

BURKER, W. \& E. R. DEARDORFF, 1970 - Simultaneous spectrophtometric determination of cobalt, nickel and copper with 2, 3- quinoxalinedithiol. Talanta, 17(255-64).

CHARLOT, G., 1964 - Colorimetric Determination of Elements. (trad da 12. ${ }^{\mathrm{a}}$ ed. francesa) Elsevier Publishing Company - Amsterdam - London New York, $449 \mathrm{pp}$.

CLARK, L. J., 1958 - Cobalt determination in soil and rocks with 2-nitroso-1naphthol. Anal. Chem. 30(6):1153-56.

HAROLD, F. V. \& E. SZOBOLOTZKY, 1963 - Determination of microgram quantities of cobalt in beer. J. of the Inst. of Brewing. 69(253-58).

HOLLAND, W. J. \& J. BOZIC, 1968 - Rapid spectrophotometric determination of cobalt with 2,2' - dipyridyl ketoxime. Talanta, 15(843-47).

SANDELL, E. B., 1959 - Colorimetric Determination of traces of Metals, 3rd Ed. New York, Interscience Publishers Inc., 1032 pp. (Chemical Analysis, Vol. III). 